\title{
Vitamin deficiencies and prevention methods after bariatric surgery
}

\author{
Sema Çalapkorur ${ }^{1}$, Hürmet Küçükkatirci² \\ 'Erciyes University, Health Science Faculty, Department of Nutrition and Dietetics, Kayseri 38000, Turkey. \\ ${ }^{2}$ Kapadokya University, School of Health Sciences, Department of Nutrition and Dietetics, Nevşehir 50000, Turkey.
}

Correspondence to: Dr. Res. Assist. Sema Çalapkorur, Erciyes University, Health Science Faculty, Department of Nutrition and Dietetics, Kayseri 38000, Turkey. E-mail: dyt_sema@hotmail.com

How to cite this article: Çalapkorur S, Küçükkatirci H. Vitamin deficiencies and prevention methods after bariatric surgery. Mini-invasive Surg 2020;4:15. http://dx.doi.org/10.20517/2574-1225.2019.51

Received: 14 Nov 2019 First Decision: 18 Dec 2019 Revised: 12 Feb 2020 Accepted: 13 Feb 2020 Published: 11 Mar 2020

Science Editor: Wah Yang Copy Editor: Jing-Wen Zhang Production Editor: Tian Zhang

\begin{abstract}
Bariatric surgeries have proven to be an effective treatment for morbid obesity to reduce the excess body weight of the individuals. Besides weight loss and improvement in metabolic parameters, bariatric surgery procedures can also cause some complications. One of the most common complications observed after bariatric surgery is vitamin deficiencies. Vitamin deficiencies occur due to malabsorptive surgery in patients with absorption disorder and restrictive surgery in patients with inadequate intake. These deficiencies may be accompanied by systematic and neurological findings. Therefore, regular follow-up of patients after bariatric surgery is crucial. If any vitamin deficiency is detected in the patient clinically or biochemically, it is recommended to eliminate this deficiency through supplementation.
\end{abstract}

Keywords: Obesity, bariatric surgery, vitamin deficiency, supplementation

\section{INTRODUCTION}

Obesity is a public health problem characterized by excessive fat accumulation in adipose tissue resulting from the complex relationship among the genetic, socioeconomic, and cultural factors and the imbalance between energy intake and expenditure ${ }^{[1,2]}$. Especially morbid obesity [body mass index (BMI) $\left.\geq 40 \mathrm{~kg} / \mathrm{m}^{2}\right]$ adversely affects the quality of life of the individual and is associated with many chronic diseases ${ }^{[3,4]}$.

In recent years, there has been an increase in the frequency of application of bariatric surgical methods due to the increase in the prevalence of morbid obesity, raising public awareness regarding obesity, and 
improvements in surgical procedures ${ }^{[5,6]}$. The goal of bariatric surgery, which is an effective treatment for morbid obesity, is to achieve weight loss in the patient and improve his/her quality of life ${ }^{[5]}$.

Bariatric surgery methods are classified as restrictive, malabsorptive, and combined methods according to the effect mechanism. In restrictive methods, a small gastric sac is created to limit the amount of food the patient can consume at one time. In malabsorptive methods, a part of the small intestine is bypassed and consequently the absorption of nutrients decreases. In combination methods, both mechanisms are used to achieve weight loss ${ }^{[7]}$.

Several studies have shown that bariatric surgical procedures ensure weight loss and improvement in metabolic parameters in morbidly obese individuals ${ }^{[8-10]}$. However, these individuals need to be evaluated for long-term complications of the surgery ${ }^{[11]}$. One of the most common complications after bariatric surgery is vitamin deficiencies. Vitamin deficiencies have been observed in patients who underwent malabsorptive surgery due to absorption disorder and in patients who underwent restrictive surgery due to inadequate intake ${ }^{[12]}$.

In a study conducted on subjects during the first year following a Roux-en-Y gastric bypass (RYGB), which is a malabsorptive method, vitamin A deficiency in $11 \%$ of patients, vitamin C deficiency in $34.6 \%$ of patients, vitamin D deficiency in $7 \%$ of patients, thiamine deficiency in $18.3 \%$ of patients, riboflavin deficiency in $13.6 \%$ of patients and vitamin B12 deficiency in $13.6 \%$ of patients were found ${ }^{[13]}$. Similarly, in another study, in the first year following RYGB, vitamin D deficiency in $12 \%$ of patients, vitamin B12 deficiency in $60 \%$ of patients, and folic acid deficiency in $47 \%$ of patients were determined ${ }^{[14]}$.

Literature data show that patients who have undergone bariatric surgery are at risk for vitamin B12, thiamine, folic acid, and vitamin $\mathrm{A}, \mathrm{D}$, and $\mathrm{K}$ deficiency ${ }^{[15-19]}$. These deficiencies in patients can be observed in a wide range together with systematic and neurological findings. Therefore, regular monitoring of vitamin levels as well as initiating supportive treatment in the case of deficiency is very important ${ }^{[20]}$.

This review aims to provide information about vitamin deficiencies seen after bariatric surgeries and prevention methods in the light of the literature.

\section{WATER-SOLUBLE VITAMINS}

\section{Thiamine}

It is reported that thiamine deficiency, which usually occurs within 4-6 weeks after surgery, is observed in approximately $30 \%$ of patients ${ }^{[12]}$. For this reason, the European Federation of Neurological Societies recommends postoperative monitoring of the thiamine levels of patients for at least 6 months and, where necessary, performing parenteral thiamine supplementation ${ }^{[21]}$.

A 100-mg oral thiamine supplementation twice a day is the standard treatment for thiamine deficiency. Patients with symptoms of Wernicke's encephalopathy or acute psychosis need to be kept under medical surveillance in the hospital. These patients should receive at least $250 \mathrm{mg} /$ day thiamine intramuscularly or intravenously for 3-5 days ${ }^{[20,22,23]}$. If thiamine deficiency after bariatric surgery cannot be treated with oral thiamine supplementation, it is associated with excessive bacterial growth in the small intestine. Antibiotic treatment is needed to overcome this deficiency, which is called bariatric beriberi ${ }^{[15]}$.

\section{Riboflavin}

Biochemical rather than clinical riboflavin deficiency was reported after bariatric surgery ${ }^{[13]}$. If there are findings associated with riboflavin deficiency such as dermatitis, stomatitis, and glossitis in patient, and riboflavin deficiency is also observed biochemically, riboflavin deficiency should be eliminated with 5-10 mg/day oral riboflavin supplementation ${ }^{[20,23,24]}$. 


\section{Folate}

Folate acts as a cofactor in the synthesis of methionine, thymidine, and purine nucleotides. Folate deficiency, which occurs as a result of not eating a sufficient and balanced diet, is associated with anorexia, weight loss, and weakness in individuals ${ }^{[20,24,25]}$. After bariatric surgery, an average of $38 \%$ of patients are reported to have folate deficiency and this deficiency progresses asymptomatically ${ }^{[12]}$. In the study conducted by Gudzune et al. ${ }^{[14]}$, vitamin D, iron, vitamin B12, and folate levels were evaluated in the first year after RYGB. The prevalence of folate deficiency was reported to be $13 \%$ in the first year following the operation in patients who underwent RYGB. In this study, it was emphasized that preoperative and postoperative micronutrient levels of patients were not evaluated and micronutrient deficiencies were common in the evaluated parameters.

Folate deficiency can be treated with 1-5 mg/day oral folic acid supplementation ${ }^{[20,23,24]}$.

An increase in serum folic acid levels after bariatric surgery is indicative of excessive bacterial growth in the small intestine. This is because some bacteria present in the intestinal flora are capable of synthesizing folic acid ${ }^{[25]}$. Excess bacterial proliferation in the small intestine is a disorder observed frequently after the bariatric surgery that changes the intestine structure ${ }^{[26]}$. Therefore, patients should also be evaluated for the intestinal malabsorptive disease after bariatric surgery ${ }^{[24]}$.

\section{Vitamin B12}

Vitamin B12 deficiency is quite common in older individuals, vegetarians, pregnant women, and people with kidney or intestinal disease ${ }^{[27]}$. After bariatric surgery, vitamin B12 deficiency was observed in 4\%-62\% of patients and it was argued that the deficiency occurred mostly due to duodenal bypass ${ }^{[12,24,28]}$. A selective literature review was performed by Weng et al. ${ }^{[29]}$, who reported that preoperative vitamin B12 prevalence was $2.3 \%$ and postoperative prevalence in the 12 th month after the operation was $6.5 \%$. In another study, 75 patients with a mean age of 49 were studied; weight loss and nutrient deficiencies were evaluated. According to the results of this study, prevalence of vitamin B12 deficiency increased to $61.8 \%$ five years after RYGB operation ${ }^{[28]}$.

Malabsorption and insufficient food intake were reported as the main reasons for vitamin B12 deficiency in patients who underwent bariatric surgery. Additionally, postoperative food intolerance and bacterial overgrowth in the small intestine were also suggested as causes of the deficiency. Reduction of B12 absorption in the distal ileum as a result of the loss of intrinsic factor-secreting cells, gastric acid suppression therapy with $\mathrm{H}_{2}$-receptor blockers, and the use of proton-pump inhibitors are other pathophysiological mechanisms leading to the development of vitamin B12 deficiency in patients ${ }^{[29]}$.

Vitamin B12 depots of the liver and kidney may delay postoperative deficiency for up to three years. Therefore, vitamin B12 deficiency can also be observed several years after the operation ${ }^{[28]}$.

In a study conducted on patients who underwent sleeve gastrectomy (SG), it was reported that, contrary to the literature, serum B12 levels increased significantly in the third postoperative month compared to preoperative data. In this study, $85 \%$ of patients reported that they received B12 supplementation and the increase in serum B12 levels was associated with this condition ${ }^{[30]}$.

Effective treatment methods of vitamin B12 deficiency was reported as orally 500-2000 $\mu \mathrm{g} /$ day B12 support, 1000-3000 $\mu \mathrm{g}$ intramuscular B12 support every six months, $500 \mu \mathrm{g}$ nasal B12 support once a week, or $500 \mu \mathrm{g}$ sublingual B12 support once a day ${ }^{[20,23,28]}$.

\section{Vitamin C}

The deficiency of vitamin $\mathrm{C}$ was reported to be common in the first year following the RYGB, occurring in $34.6 \%$ of patients ${ }^{[13]}$. The studies conducted on the subject reported that the deficiency increased in the first year and continued for 2 years following the surgery ${ }^{[31,32]}$. 
It is recommended that vitamin $\mathrm{C}$ deficiency, which is observed frequently after bariatric surgery, should be treated with $200 \mathrm{mg} /$ day oral vitamin C supplementation ${ }^{[20,23,24]}$.

\section{Biotin}

Biotin deficiency after bariatric surgery has not been reported in studies examining biotin deficiency after bariatric surgery ${ }^{[3,34]}$. A case regarding the loss of sense of taste after SG is reported in the literature. The patient's loss of taste was eliminated by oral biotin supplementation of $20 \mathrm{mg} /$ day for several weeks ${ }^{[20,23,35]}$.

\section{FAT-SOLUBLE VITAMINS}

\section{Vitamin A}

Data from the literature suggest that vitamin A deficiency is more common in patients who have undergone biliopancreatic diversion (BPD) and RYGB surgeries in which the duodenal channel was bypassed ${ }^{[36,37]}$. The presence of bile and bile acids in this channel was suggested as the cause of this situation. The relative reduction in bile and bile acids is accompanied by the deconjugation of bile acids, which occurs as a result of bacterial overgrowth in the small intestine, and, thus, vitamin A deficiency is observed in patients ${ }^{[24]}$.

In the studies on the subject, it was also reported that 10\%-11\% of vitamin A deficiency occurs in the first year following RYGB and $\mathrm{BPD}^{[36,38]}$.

As an initial treatment for vitamin A deficiency, 10,000 international unit (IU)/day vitamin A oral supplementation is recommended. Since $\beta$-carotene-related vitamin A toxicity was not reported in the literature, the use of this compound in the treatment of vitamin A deficiency is recommended ${ }^{[20,23,24]}$.

\section{Vitamin D}

Vitamin D deficiency is a condition observed frequently after bariatric surgery that causes bone losses and fractures, thus morbidity in the long term ${ }^{[39]}$. After bariatric surgery, decreased absorption areas in the small intestine, pancreatic secretion, and changes in bile distribution are the factors that lead to decreased absorption of vitamin $\mathrm{D}^{[40]}$.

Vitamin D deficiency is also quite common in morbidly obese patients waiting for bariatric surgery. The prevalence of vitamin D deficiency before surgery is reported to be between $54 \%$ and $80 \%$. Inadequate vitamin $\mathrm{D}$ intake, insufficient exposure to sunlight, and low bioavailability of vitamin $\mathrm{D}$ are reported as the reasons for this condition ${ }^{[40]}$. In the case of vitamin $\mathrm{D}$ deficiency, parathyroid hormone levels increase in order to maintain calcium balance in the body. This secondary hyperparathyroidism effect increases bone resorption and is associated with osteoporosis and osteomalacia in adults ${ }^{[41]}$. It is reported in the literature that the prevalence of secondary hyperparathyroidism after bariatric surgery is up to $58 \%{ }^{[42]}$. Due to the increased incidence of secondary hyperparathyroid syndrome and vitamin D deficiency after surgery, the effect of different surgical procedures on vitamin D levels has been investigated in several studies ${ }^{[13,43-47]}$.

Studies have shown that vitamin D deficiency is observed only after SG, which is known as a restrictive $\operatorname{method}^{[43,44]}$. In a study following patients for one year after SG, vitamin D deficiency was found in $39 \%$ of patients despite using daily multivitamin support ${ }^{[43]}$. In another study, a significant loss in bone mass and bone structure was observed one year following $\mathrm{SG}^{[44]}$.

Vitamin D deficiency was reported to be $7 \%$ in the first year following RYGB, which is a malabsorptive method $^{[13]}$. This rate was reported to be $65 \%$ in the 10th postoperative year and suggested to be due to increased levels of parathyroid hormone ${ }^{[41]}$.

The prevalence of vitamin D deficiency was determined as 63\% in the fourth year after BPD and 73\% in the eighth year ${ }^{[45,46]}$. In adjustable gastric band surgery, vitamin D deficiency has been reported to be the second most common micronutrient deficiency after iron $(\mathrm{Fe})$ deficiency ${ }^{[47]}$. 
Data from the literature indicate that vitamin D deficiency is observed following many bariatric procedures ${ }^{[13,42-47]}$. In these patients, it is known that bone turnover is accelerated in relation to low bone mineral density and this poses a risk for bone fractures. Therefore, it is very important to regularly monitor the vitamin D levels of patients after surgery and, if necessary, provide vitamin D supplementation ${ }^{[24,48,49]}$.

In the treatment of vitamin D deficiency, 50,000 IU ergocalciferol support once a week for 12 weeks, and then, 1000-5000 IU/day cholecalciferol support is recommended ${ }^{[20,23]}$. In patients with osteomalacia, 50,000 IU ergocalciferol should be given once a week and 600,000 IU ergocalciferol supplementation in total should be reached in 12 weeks. However, there is also evidence that high-dose oral vitamin D supplementation causes liver abnormalities and hypercalcemia. Therefore, patient follow-up should be performed regularly during and after supplementation ${ }^{[24]}$.

\section{Vitamin E}

In the study carried out by Cuesta et al. ${ }^{[38]}$, anthropometric measurements and vitamin levels of 178 patients who underwent 116 RYGB and 62 BPD operations were evaluated before and after surgery. In the first year following RYGB, vitamin E deficiency was not found in the patients and the prevalence of vitamin E deficiency was $4.8 \%$ in the first year following BPD.

In case of deficiency, 800-1200 IU/day oral vitamin E supplementation was recommended ${ }^{[20,23,24]}$.

\section{Vitamin K}

Vitamin K deficiency was reported to be rare in the short term after RYGB. Nevertheless, in a study in which BPD patients were followed up for 42 months, vitamin K deficiency was determined in $60 \%$ of patient ${ }^{[50]}$.

It is recommended that vitamin $\mathrm{K}$ deficiency be treated with either 2.5-25.0 $\mathrm{mg} /$ day of vitamin $\mathrm{K}$ taken orally or 5-15 mg parenteral vitamin K supplementation taken intramuscularly or subcutaneously ${ }^{[20,23,24]}$.

\section{CONCLUSION AND RECOMMENDATIONS}

One of the most common complications observed in patients after bariatric surgery is vitamin deficiencies. These deficiencies can negatively affect the quality of life, nutritional behavior, and the goals that are desired to be achieved after surgery by causing many biochemical and clinical disorders in patients. Therefore, regular follow-up of patients after surgery is very important. If any vitamin deficiency is detected in the patient biochemically or clinically, relevant vitamin deficiency should be eliminated immediately through supplementation.

It was reported that vitamin deficiencies are more common in malabsorptive surgery methods; therefore, the patient's bariatric surgery procedure should also be considered while applying vitamin supplementation.

In patients who underwent restrictive surgery, adequate and balanced nutrition should be provided after surgery via the nutrition programs prepared by expert dietitians to prevent vitamin deficiency.

In addition, vitamin deficiencies that exist before surgery in patients may get worse after surgery. Therefore, vitamin levels should be evaluated before surgery and if there is deficiency it must be treated before the operation.

\section{DECLARATIONS}

\section{Authors' contributions}

Did the literatüre review, summarized the studies on the subject: Küçükkatirci $\mathrm{H}$ Made the studies that are summarized on the subject into an article: Çalapkorur S Reviewed and approved the final version of the article: Çalapkorur S, Küçükkatirci $\mathrm{H}$ 


\section{Availability of data and materials}

Not applicable.

\section{Financial support and sponsorship}

None.

\section{Conflicts of interest}

Both authors declared that there are no conflicts of interest.

\section{Ethical approval and consent to participate}

Not applicable.

\section{Consent for publication}

Not applicable.

\section{Copyright}

(C) The Author(s) 2020.

\section{REFERENCES}

1. Apovian CM. Obesity: definition, comorbidities, causes, and burden. Am J Manag Care 2016;22:176-85.

2. Gao M, Liu D. Gene therapy for obesity: progress and prospects. Discov Med 2014;17:319-28.

3. Seidell JC, Halberstadt J. The global burden of obesity and the challenges of prevention. Ann Nutr Metab 2015;66:7-12.

4. Li Q, Blume SV, Huang JC, Hammer M, Ganz ML. Prevalence and healthcare costs of obesity-related comorbidities: evidence from an electronic medical records system in the United States. J Med Econ 2015;18:1020-8.

5. SAGES Guidelines Committee. Guidelines for clinical application of laparoscopic bariatric surgery. Available from: https://www.sages. org/publications/guidelines/guidelines-for-clinical-application-of-laparoscopic-bariatric-surgery/ [Last accessed on 19 Feb 2020]

6. Fried M, Yumuk V, Oppert JM, Scopinaro N, Torres AJ, et al. Interdisciplinary european guidelines on metabolic and bariatric surgery. Obes Facts 2013;6:449-68.

7. Brethauer SA, Chand B, Schauer PR. Risks and benefits of bariatric surgery: current evidence. Cleve Clin J Med 2006;73:993-1007.

8. Auguet T, Terra X, Hernández M, Sabench F, Porras JA, et al. Clinical and adipocytokine changes after bariatric surgery in morbidly obese women. Obesity (Silver Spring) 2014;22:188-94.

9. Våge V, Sande VA, Mellgren G, Laukeland C, Behme J, et al. Changes in obesity-related diseases and biochemical variables after laparoscopic sleeve gastrectomy: a two-year follow-up study. BMC Surg 2014;14:8-14.

10. Aftab H, Risstad H, Søvik TT, Bernklev PDT, Hewitt S, et al. Five-year outcome after gastric bypass for morbid obesity in a Norwegian cohort. Surg Obes Relat Dis 2014;10:71-8.

11. Tack J, Deloose E. Complications of bariatric surgery: dumping syndrome, reflux and vitamin deficiencies. Best Pract Res Clin Gastroenterol 2014;28:741-9.

12. Concors SJ, Ecker BL, Maduka R, Furukawa A, Raper SE, et al. Complications and surveillance after bariatric surgery. Curr Treat Options Neurol 2016;18:5.

13. Clements RH, Katasani VG, Palepu R. Incidence of vitamin deficiency after laparoscopic Roux-en-Y gastric bypass in a university hospital setting. Am Surg 2006;72:1196-202.

14. Gudzune KA, Huizinga MM, Chang HY. Screening and diagnosis of micronutrient deficiencies before and after bariatric surgery. Obes Surg 2013;23:1581-9.

15. Shankar P, Boylan M, Sriram K. Micronutrient deficiencies after bariatric surgery. Nutrition 2010;26:1031-7.

16. Saltzman E, Karl JP. Nutrient deficiencies after gastric bypass surgery. Annu Rev Nutr 2013;33:183-203.

17. Alexandrou A, Armeni E, Kouskouni E, Tsoka E, Diamantis T, et al. Cross-sectional long-term micronutrient deficiencies after sleeve gastrectomy versus Roux-en-Y gastric bypass: a pilot study. Surg Obes Relat Dis 2014;10:262-8.

18. Van Rutte P, Aarts E, Smulders J, Nienhuijs S. Nutrient deficiencies before and after sleeve gastrectomy. Obes Surg 2014;24:1639-46.

19. Aron-Wisnewsky J, Verger EO, Bounaix C, Dao MC, Oppert JM, et al. Nutritional and protein deficiencies in the short term following both gastric bypass and gastric banding. PLoS One 2016;11:e149588.

20. Rashti F, Gupta E, Shope TR, Koch TR. Overview of nutritional deficiencies after bariatric surgery. Diet Nutr Critical Care 2015;3:1079-92.

21. Galvin R, Bråthen G, Ivashynka A, Hilbom M, Tanesescu R, et al. EFNS guidelines for diagnosis, therapy and prevention of Wernicke encephalopathy. Eur J Neurol 2010;17:1408-18.

22. Thomson AD, Marshall EJ. The treatment of patients at risk of developing Wernicke's encephalopathy in the community. Alcohol Alcohol 2006:41:159-67.

23. Mechanick JI, Youdim A, Jones DB, Garvey WT, Hurley DL, et al. Clinical practice guidelines for the perioperative nutritional, metabolic, and nonsurgical support of the bariatric surgery patient - 2013 update: cosponsored by American Association of Clinical 
Endocrinologists, the Obesity Society, and American Society for Metabolic \& Bariatric Surgery. Obesity 2013;9:159-91.

24. Bal BS, Finelli FC, Shope TR, Koch TR. Nutritional deficiencies after bariatric surgery. Nat Rev Endocrinol 2012;8:544-56.

25. Camilo E, Zimmerman J, Mason JB, Golner B, Russel R, et al. Folate synthesized by bacteria in the human upper small intestine is assimilated by the host. Gastroenterology 1996;110:991-8.

26. Lakhani SV, Shah HN, Alexander K, Finelli FC, Kirkpatrick JR, et al. Small intestinal bacterial overgrowth and thiamine deficiency after Roux-en-Y gastric bypass surgery in obese patients. Nutr Res 2008;28:293-8.

27. Herrmann W, Obeid R. Causes and early diagnosis of vitamin B12 deficiency. Dtsch Arztebl Int 2008;105:680-5.

28. Dalcanale L, Oliveira CP, Faintuch J, Nogueira MA, Rondó P, et al. Long-term nutritional outcome after gastric bypass. Obes Surg 2010;20:181-7.

29. Weng TC, Chang CH, Dong YH, Chang YC, Chuang LM. Anaemia and related nutrient deficiencies after Roux-en-Y gastric bypass surgery: a systematic review and meta-analysis. BMJ Open 2015;5:e06694.

30. Çalapkorur S, Köksal E, Şahin H, Şentürk M. Energy expenditure, hormonal physiology, and nutritional status following sleeve gastrectomy. Bariatric Surg Pract Patient Care 2019; Epub ahead of print [DOI: 10.1089/bari.2019.0050]

31. Donadelli SP, Jungueira-Franco MV, de Mattos Donadelli CA, Salgado WJR, Ceneviva R, et al. Daily vitamin supplementation and hypovitaminosis after obesity surgery. Nutrition 2012;28:391-6.

32. Netto BD, Moreira EA, Patiño JS, Benincá JP, Jordão AA, et al. Influence of Roux-en-Y gastric bypass surgery on vitamin C, myeloperoxidase, and oral clinical manifestations: a 2-year follow-up study. Nutr Clin Pract 2012;27:114-21.

33. Bodunova NA, Askerkhanov RG, Khatkov IE, Sabelnikova EA, Parfenov AI, et al. Impact of bariatric surgery on vitamin metabolisms in obese patients. Ter Arkh 2015;87:70-6.

34. Bodunova NA, Sabelnikova EA, Parfenov AI, Askerhanov RG, Tkachenko EV, et al. The change in the concentration of vitamins after bariatric surgery. Klin Med (Mosk) 2015;93:28-31.

35. Greenway FL, Ingram DK, Ravussin E, Hausmann M, Smith SR, et al. Loss of taste responds to high-dose biotin treatment. J Am Coll Nutr 2011;30:178-81.

36. Eckert MJ, Perry JT, Sohn VY, Boden J, Martin MJ, et al. Incidence of low vitamin A levels and ocular symptoms after Roux-en-Y gastric bypass. Surg Obes Relat Dis 2010;6:653-7.

37. Ramos-Leví AM, Pérez-Ferre N, Sánchez-Pernaute A, Torres García AJ, Rubio Herrera MA. Severe vitamin A deficiency after malabsorptive bariatric surgery. Nutr Hosp 2013;28:1337-40.

38. Cuesta M, Pelaz L, Pérez C, Torrejón MJ, Cabrerizo L, et al. Fat-soluble vitamin deficiencies after bariatric surgery could be misleading if they are not appropriately adjusted. Nutr Hosp 2014;30:118-23.

39. Johnson JM, Maher JW, Samuel I, Heitshusen D, Doherty C, et al. Effects of gastric bypass procedures on bone mineral density, calcium, parathyroid hormone, and vitamin D. J Gastrointest Surg 2005;9:1106-10.

40. Aarts E, van Groningen L, Horst R, Telting D, van Sorge A, et al. Vitamin D absorption: consequences of gastric bypass surgery. Eur J Endocrinol 2011;164:827-32.

41. Karefylakis C, Näslund I, Edholm D, Sundbom M, Karlsson FA, et al. Vitamin D status 10 years after primary gastric bypass: gravely high prevalence of hypovitaminosis D and raised PTH levels. Obes Surg 2014;24:343-8.

42. Youssef Y, Richards WO, Sekhar N, Kaiser J, Spagnoli A, et al. Risk of secondary hyperparathyroidism after laparoscopic gastric bypass surgery in obese women. Surg Endosc 2007;21:1393-6.

43. Aarts EO, Janssen IM, Berends FJ. The gastric sleeve: losing weight as fast as micronutrients? Obes Surg 2011;21:207-11.

44. Nogués X, Goday A, Peña MJ, Benaiges D, de Ramón M, et al. Bone mass loss after sleeve gastrectomy: a prospective comparative study with gastric bypass. Cir Esp 2010;88:103-9.

45. Slater GH, Ren CJ, Siegel N, Williams T, Barr D, et al. Serum fat-soluble vitamin deficiency and abnormal calcium metabolism after malabsorptive bariatric surgery. J Gastrointest Surg 2004;8:48-55.

46. Khandalavala BN, Hibma PP, Fang X. Prevalence and persistence of vitamin D deficiency in biliopancreatic diversion patients: a retrospective study. Obes Surg 2010;20:881-4.

47. Nadler EP, Youn HA, Ren CJ, Fielding GA. An update on 73 US obese pediatric patients treated with laparoscopic adjustable gastric banding: comorbidity resolution and compliance data. J Pediatr Surg 2008;43:141-6.

48. Berarducci A, Haines K, Murr MM. Incidence of bone loss, falls, and fractures after Roux-en-Y gastric bypass for morbid obesity. Appl Nurs Res 2009;22:35-41.

49. Balsa JA, Botella-Carretero JI, Peromingo R, Caballero C, Muñoz-Malo T, et al. Chronic increase of bone turnover markers after biliopancreatic diversion is related to secondary hyperparathyroidism and weight loss. Relation with bone mineral density. Obes Surg 2010;20:468-73.

50. Homan J, Betzel B, Aarts EO, Dogan K, van Laarhoven KJ, et al. Vitamin and mineral deficiencies after biliopancreatic diversion and biliopancreatic diversion with duodenal switch--the rule rather than the exception. Obes Surg 2015;25:1626-32. 